\section{Linguistic Landscaping at School - A Teaching Design}

Gl_Forum 2019, Issue 2

Page: 206 - 212

Short Paper

Corresponding Author:

s1013038@stud.sbg.ac.at

DOI: 10.1553/giscience2019_02_s206

\author{
Manuel Huyer \\ University of Salzburg, Austria
}

\begin{abstract}
In a Digital Humanities context, we give an overview of applications in the field of Linguistic Landscapes. Focusing on basic digital education, which is the first pillar of the digital competency model for 'School 4.0' in the Masterplan Digitalisierung in der Schule, a teaching model is currently being developed which focuses on the development and assessment of digital competences and uses various digital learning tools, allowing modern, innovative teaching. The model uses the advantages and possibilities of two subjects, Geography and German, in order to achieve the greatest possible educational value. The topic 'Linguistic Landscapes' represents just one of many intersections of the two subjects and, especially in the digital world, has potential for a wide range of applications. Because language takes place in space, it can be argued that language in its visible form in particular - for example on city streets - contributes to the shaping of the landscape. An advantage of this project is that improvements in teaching practices generally can be achieved through the digital humanities.
\end{abstract}

\title{
Keywords:
}

education, digital humanities, linguistic landscaping, lesson planning, digitalization in schools

\section{The Linguistic Landscape}

The landscape is a construct which has traditionally been associated with Geography as a scientific subject. Hard (1969) provides a broad overview of how the term 'landscape' (Landschaft) has developed since it first appeared in German literature in the early 1900s. According to Hard, the concept became known to the discipline of Geography shortly after the term was discovered by the Humanities.

Already in 1923, Hellpach writes that a landscape is a purely sensual overall impression that is awakened in us by a piece of the earth's surface and the associated section of the heavens (Hellpach, 1923). As can be seen in this definition, sensory impressions are strongly associated with the term. At the same time, Hettner states that the landscape includes earth, water, air, flora and fauna, as well as human beings and their works (Hettner, 1927, p. 231.) Through human activity, languages become visible in the form of written language. Gorter notes that a 
'Linguistic Landscape' is an "all-encompassing view on written language in the public space, paying attention to all signs" (Gorter, 2012, p.1). Visually perceivable linguistic units (words, slogans, phrases ...) are examined for the language(s) used, content, font style and size, frequency of occurrence, and the location where they can be seen. Gorter et al. believe that 'linguistic landscaping', examines [not only] the signs themselves, but also who initiates, creates, places and reads them" (Gorter, 2012, p.1). Examples of 'signs' include posters, stickers, graffiti, restaurant names, as well as street and traffic signs and so on.

According to Androutsopoulos, the linguistic landscape has two main functions - an informative function and a symbolic one. The informative function raises the question of what the linguistic landscape says about its inhabitants and users, and references the languages and ethnic composition present locally. The symbolic function reveals the presence or absence of a language and its vitality and strength (Androutsopoulos, 2008, p. 1).

\section{Qualitative investigation of signs}

The qualitative examination of signs deals in greater detail with the individual statement units. Clearly, this can be done in class only for a few selected examples if a fine-grained analysis is to be maintained.

The creator or person in charge: Is there a top-down (official) or a bottom-up (private commercial) structure in the sign under consideration? Androutsopoulos $(2008, \mathrm{p} .2)$ proposes a third category consisting of unauthorized signs, which are unlawfully affixed, and whose messages usually include mentions of rebellion or revolution. Unauthorized signs (such as tags) may also mark territorial claims.

Status of the languages involved: Are the languages used on the signs official languages, autochthonous or allochthonous minority languages, or international languages? How do they relate to one another?

Number of languages on the same sign: How is the semantic relationship between various languages made apparent? For instance, a sign may express the same meaning in several languages, employ verbatim translations, or one part may be in one language while another is in a different language. We can look at individual elements of a sign and identify the fonts and colours used, the sign's lay-out, and the font size, and how the various elements relate to each other. An example can be seen in Section 7 (Figure 3).

\section{Quantitative investigation of signs}

A sample area of investigation can be found on Google Maps using the hyperlink http://bit.ly/linguisticlandscapesalzburg (GOOGLE, n.d.). By left-clicking on one of the bubble icons, a window with the following picture will appear: 


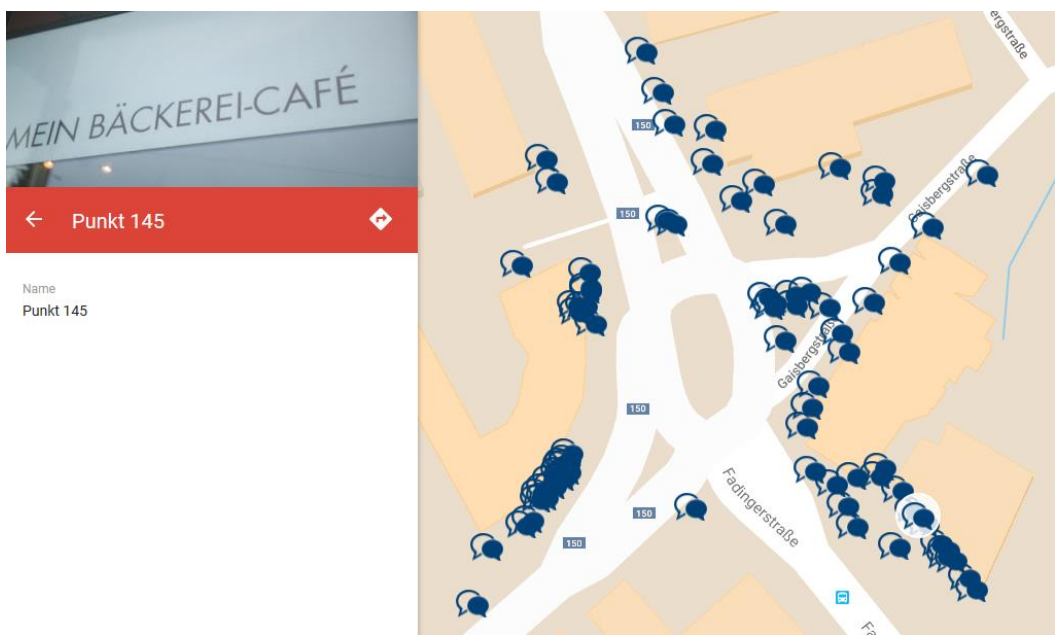

Figure 1: Illustration of one area from the map

Another click on the image allows a full-screen view. A button bottom-left allows the base map to be replaced by a satellite image or a simple street map. (All photos included in the Google-Map were taken by the author.)

\section{General conditions - The question of when and where}

Having trialled the course, and given the approach used, we would say that the Linguistic Landscaping course is suitable only for upper grades. The course requires ready access to smartphones and computers as the key platforms on which the lessons are taught. The Masterplan Digitalisierung in der Bildung mentions a revision of school curricula towards a comprehensive consideration of digital skills, pointing to a need for action in the development and acquisition of digital teaching and teaching materials for classes (BMBWF).

At least one laptop and a projector are required, and one smartphone per student. Studentowned devices may be used. Students may work in pairs or small groups if necessary. Openair classes have also been planned. The curriculum of the 'Neue Oberstufe' for 'Geographie und Wirtschaftskunde' states that that geographic and economic information can be obtained, analysed and displayed in a target-group-oriented manner using computer-assisted procedures. Especially in upper secondary schools, students should be able to classify spatial information independently, as a basic competence. A didactic principle of geography teaching states that students should learn through practical work incorporated into certain course modules for every subject matter. 


\section{The course design}

Given that most pupils have at the very least a basic understanding of maps, 'Linguistic Landscaping' should feature in lessons in tandem with digital maps (OSM, Google Maps, ESRI applications). In our project, it is important for pupils to be able to mark locations on digital maps, label them, and complement them with pictures. During German lessons, pupils should come to understand the meaning of 'signs', as well as become familiar with theory and the specific tools needed for conducting research. The course subject Geography first introduces pupils to digital maps. Students then carry out field work (best done in a city area) during which they collect data in the immediate vicinity of the school or elsewhere. This involves taking photos, with digital cameras or smartphones, of all sorts of written language that will later be evaluated in class. The use of central, app-based software is highly recommended, as this facilitates later processing considerably. For example, apps such as 'geo-editor' or 'geotag photos' allow photo locations to be added directly to a map. Another possibility is for smartphones to automatically add geotags to the photos when the GPS is turned on. The geotags can then be read out loud.

After collective or individual data collection, the photos are first mapped, then analysed, interpreted and discussed. The map example given in Figure 1 shows how such a map could look. Later, the photos are examined according to the quantitative and qualitative criteria described in Sections 2 and 3 above. While German lessons are particularly suited for qualitative investigations, as they can be used to interpret individual 'signs', Geography lessons lend themselves well to comparing quantitative results, for example the demographic data of different areas. Further examples of quantitative and qualitative evaluations can be found in the Sections 6 and 7.

\subsection{Learning goals}

This learning environment contributes to the ability to read and create digital maps, analyse and interpret digital data, and understand their implications. Furthermore, one of the goals for students is to explore and get to know the city or area around their school and to delve more deeply into the city's structure. A deeper understanding of space and landscape concepts should accordingly be achieved. The German courses may also include statistical data analysis, but we believe that the qualitative examination of signs offers many more creative possibilities.

\subsection{Methods and Media}

As the possibilities of digital media are enormous and ever-changing, an increasing number of opportunities present themselves. As educators, we must act in the knowledge that teachers live in a different digital world from the one their students inhabit. But neither group is homogeneous.

We can benefit from so-called 'sharing cultures', also known as the 'cloud'. This means that the knowledge and efforts of many individuals together create greater value. In our project's case, the collective efforts of students to collect photos are more efficient and better planned than would be possible if such tasks were performed individually. In addition, everyone has 
his/her own strengths and can incorporate them into the project. The students should appreciate the possibilities of cooperation and work cooperatively.

The end result should look something like the one that is linked in lesson planning (see Figure 1). To achieve this, upload all students' photos into either Dropbox or a folder on Google Drive, after which they will be marked in Google Maps. This requires a Google Account. By following the path Menu $\rightarrow$ My Places $\rightarrow$ Maps $\rightarrow$ Create Map, you can start a new project. Markers can be selected by using the marker symbol below the search bar; by left-clicking on the map, a marker can be set and later moved. You can give the marker a name, add a description, and most importantly, upload a photo. However, manually editing the map is very time-consuming, making it more efficient to use either a common Google Account which all students can log into, or a geotag-app, in which case the use of a common account remains the better option. Using a common Google account allows each student to create their own layer to better visualize the results. For example, the students could name their layer using their names. It also allows an efficient overview for the educator. In the second alternative, working with an app, the location on the map is identified automatically. Many possibilities are offered by the 'Geotag Photos' app, of which a free version exists for both Android and Apple. The routes covered can also be visualized in this app.

\section{Example (Altstadt Salzburg) - Quantitative aspect}

Only 2,497 main residences are registered in the Altstadt/Mülln district of Salzburg. One explanation is that many second homes are located here. 19- to 29-year-olds and 30- to 39year-olds are the most represented age groups. Over-70s account for just over 10\%. 63\% of the people who live in the Altstadt are Austrian citizens.

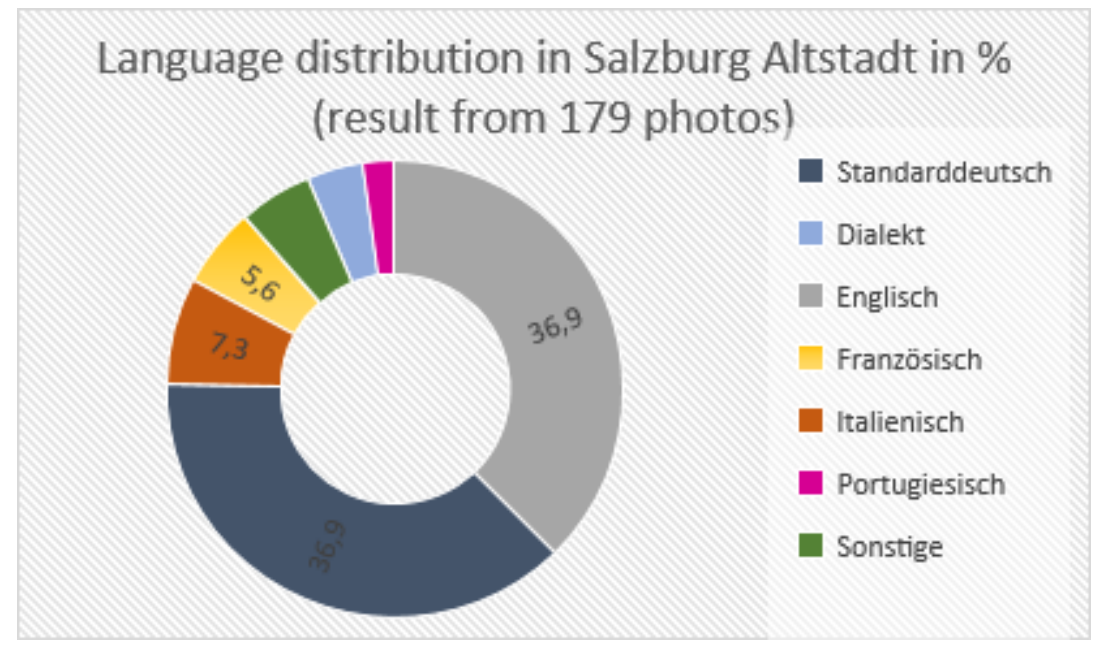

Standard German Local Dialect English French Italian Portuguese Other

Figure 2: Language distribution in Altstadt/Mülln. Data source: own data collection. 
German and English are represented equally in the Altstadt, on about $37 \%$ of the signs analysed for linguistic content. Together, they account for roughly three-quarters of all linguistic expressions. French and Italian occupy the third and fourth places. Boasting fifteen languages, linguistic diversity in the centre is very high: the city centre is clearly a tourist hub.

\section{Example (a picture taken in Lehen) - Qualitative aspect}

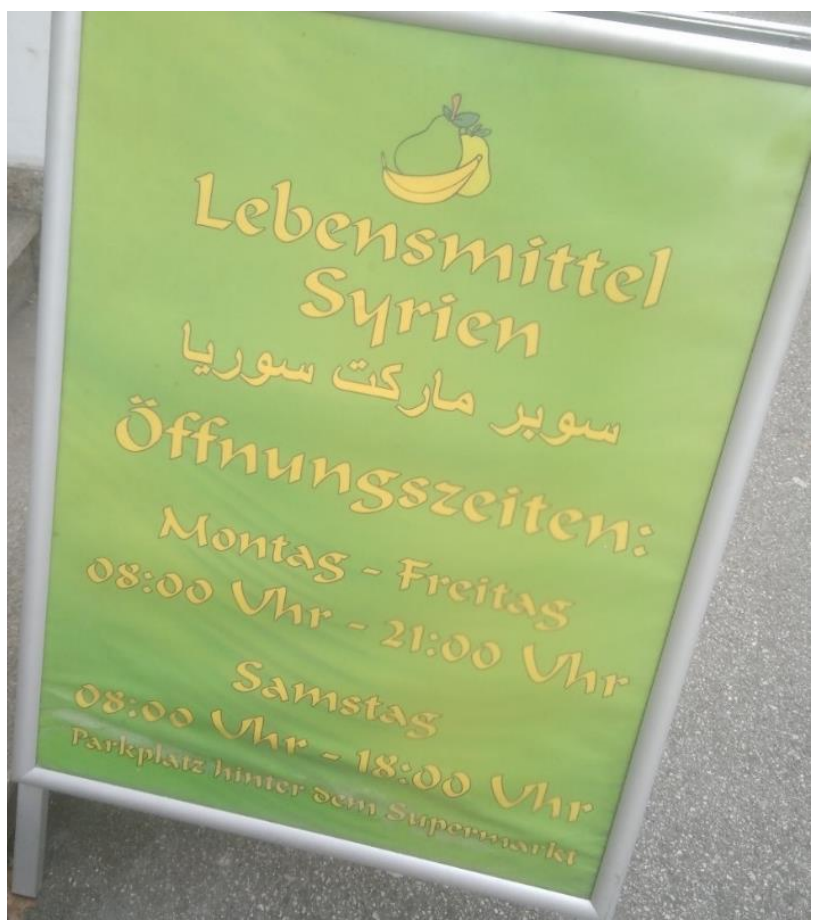

Figure 3: Syrian food (Lehen)

The photo is of a billboard outside a grocery store in Lehen which offers Syrian food. Beneath a large heading in German is a slightly smaller-sized text in Arabic. It is not an accurate translation, because 'سوبرماركت سوريا' means 'Syria supermarket'. These two expressions refer to the name of the business. Anything regarding organizational matters (shop opening times) is in German. Two languages are included - German as the official language and Arabic as the language of a minority. From the amount of text, its position and size, we can deduce that the Arabic language on this sign is subordinated to the German language. Although the font colour is uniform yellow, we can hardly compare the fonts because the languages use different scripts. We may deduce from the sign that its authors are probably the owners of the shop, and that they are Syrian or at least Arabic speakers: the heading appears to be an imperfect translation into German and should read 'Syrische Lebensmittel' or 'Lebensmittel aus Syrien' in idiomatic German. It is a private commercial signboard, which advertises the business to passers-by.

\section{Conclusion}

The importance of the linguistic landscape for schools is a given, especially in times of increasing migration which characterizes an intercultural society. This also applies to the school, where many different cultures interact.

As illustrated in Section 7, German is not the only language shaping the urban landscape. Many languages are visibly present. For students in school, this is a perfect way to get to know the 
city better and to understand how complex its appearance, structure and demographical composition can be. Using the methodology employed in the 'Linguistic Landscaping' course, which offers an excellent point of contact between German courses and Geography courses, students familiarize themselves with new techniques and interact intensively with language and space. In conclusion, this course appears to hold promise. Integrating it as part of the school curriculum is likely to offer strong educational value and increased awareness of society for participating pupils.

\section{References}

Androutsopoulos, J. (2008). ,Linguistic landscapes: Visuelle Mehrsprachigkeitsforschung als Impuls an die Sprachpolitik'. Lecture at the international symposium „Städte-Sprachen-Kulturen“ (September 17th -19th, 2008), Mannheim. p. 1-2.

BMBWF. ,Masterplan Digitalisierung in der Bildung'. Lecture to the Council of Ministers (September 5th, 2018)

GOOGLE (n.d..: Linguistic Landscape Salzburg. Retrieved from: https://goo.gl/maps/1r6ygdQ25173BQbQ7.

Gorter, D. et al. (2012). Studying Minority Languages in the Linguistic Landscape. Basingstoke: Palgrave Macmillan. p. 1.

Hard, G. (1969). Die Diffusion der „Idee der Lanschaft“. Primärlinien zu einer Geschichte der Landschaftsgeographie. In: Erdkunde 24(4), 249-264.

Hellpach, W. (1923). Die geopsychischen Erscheinungen. Wetter und Klima, Boden und Landschaft in ibrem Einfluß auf das Seelenleben. Leipzig: Wilhelm Engelmann.

Hettner, A. (1927). Die Geographie, ihre Geschichte, ibr Wesen und ihre Methoden. Breslau: Hirt. p. 231.

Stadtgemeinde Salzburg: Einwohner- und Bevölkerungsstatistik. Statistische Zählbezirke und Zählsprengel. https://www.stadt-salzburg.at/internet/bildung_kultur/salzburg_in_zahlen/einwohner_bevoelker u_321402/statistische_zaehlbezirke_und_zaehlspren_251948.htm. 